\author{
GEORGE L. PERRY* \\ Brookings Institution
}

\title{
Changing Labor Markets and Inflation
}

WHAT RATES OF INFLATION will accompany various unemployment rates? This question is the central concern of stabilization policy today and also a major source of uncertainty for economic forecasting. Whether the approach was made through informed judgment or rigorous research, investigators have sought the answer to this question in the historic relation between unemployment rates, on the one hand, and rates of wage increase on the other, with wage increases then used to explain inflation. With many variations and refinements, this concept of a trade-off between wage changes and the aggregate unemployment rate has been the framework for most discussions of inflation during the past decade.

In this view of the inflationary process, the aggregate unemployment rate has served as a proxy for the tightness of labor markets. But significant changes have been taking place in the composition of the labor forcenotably an increase in the proportion of teenagers and women-and in the unemployment experience of different age-sex groups. As a result, the aggregate unemployment rate in recent years has been an increasingly misleading proxy for comparing the current labor market with earlier ones. A given unemployment rate is associated with a tighter overall labor market today than it was ten or twenty years ago. And this means that the trade-off between inflation and the aggregate unemployment rate has shifted: To-

* I want to acknowledge the research assistance I received from Nancy Hwang and Janet Kelly. 
day, a given unemployment rate is associated with a more inflationary rate of wage change than it was in the earlier periods.

This finding rests on some measures of labor market tightness that I have developed for explaining and predicting wage changes. These are the concept of a weighted unemployment rate, in which individuals are weighted by an estimate of what they would produce if employed, and a measure of the dispersion of unemployment. Together they form a better indicator of labor market tightness than the aggregate unemployment rate alone. By this new indicator, labor markets were tighter during 1968 and 1969 than at any previous period in the postwar years. This helps explain the high rate of wage increases and inflation that the U.S. economy has suffered. And it documents the growing need for structural policies in the labor market to reduce the inflation associated with a full employment economy.

\section{Measures of Labor Market Tightness}

There are various conceptual objections to using the aggregate unemployment rate to measure labor market tightness. For instance, many (including myself) argue that what matters is the difference between available jobs and available employees to fill those jobs: This difference, rather than unemployment rates alone, should therefore be used as a measure of labor market tightness. If unemployment is conceived as an indicator of the gross excess supply of labor and vacancies as an indicator of gross excess demand, then subtracting vacancies from unemployment should provide an indicator of the net excess supply. Unfortunately, no comprehensive U.S. vacancy statistics exist, so the practical importance of this point is hard to test. The scattered information available about vacancies, together with some conceptualized models of the employment process, suggests that there is a close, inverse relationship between unemployment and vacancy rates. ${ }^{1}$ This means that some form of the unemployment rate itself is a useful proxy for the difference between vacancies and unemployment.

1. Charles C. Holt, "How Can the Phillips Curve Be Moved To Reduce Both Inflation and Unemployment?" in Edmund S. Phelps and others, Microeconomic Foundations of Employment and Inflation Theory (Norton, 1970), pp. 224-56. A number of papers discussing vacancy statistics are included in The Measurement and Interpretation of Job Vacancies (Columbia University Press for the National Bureau of Economic Research, 1966). 
Available data do permit some other adjustments to the aggregate unemployment rate. The most promising candidates are those whose relation to unemployment in recent years has been different from that in earlier periods. These offer the best chance of isolating independent influences in a measure of labor market tightness. And they seem most likely to determine what, if anything, is special about the recent inflationary period and what might change in the next few years. Three such adjustments are developed and tested in this paper.

First, the official employment and unemployment data count all individuals equally. A better measure of available labor supply would allow for differences in the contributions individuals make to production when they are employed. Such an adjustment is developed in this paper, leading to the concept of a weighted unemployment rate. Second, the official unemployment rate is an average over all dimensions of the national labor market. Useful adjustments to this average would account for imbalances that the average conceals, such as highly uneven unemployment experience in various sectors of the labor market. A measure of unemployment dispersion is developed in this paper to capture some of these effects. Third, the official unemployment concept includes only individuals actively looking for jobs. Some have argued that the appropriate unemployment concept should include individuals who are not in the job market but who would be if the demand for labor were greater. ${ }^{2}$ This concept, too, is tested below.

Each of these adjustments makes use of the substantial changes that have been taking place over time in the age-sex composition of the labor force and in the unemployment experience of the age-sex groups. Table 1 illustrates these trends. The left half of the table shows the percent of the total labor force in each group. In 1955, men of ages 25 to 64 (which I call the prime-age group, although that term is more often used for a narrower age range) constituted 56 percent of the work force, while in 1969 they constituted 48 percent. At the same time there were large increases in the proportion of both women and young people of both sexes in the labor force. The right half of the table shows the change in the unemployment rates of other groups, relative to prime-age males, that has accompanied the steady decline in the latter group's proportion in the work force. This

2. N. J. Simler and A. Tella, "Labor Reserves and the Phillips Curve," Review of Economics and Statistics, Vol. 50 (February 1968), pp. 32-49; and Robert J. Gordon, "The Recent Acceleration of Inflation and Its Lessons for the Future," Brookings Papers on Economic Activity (1:1970), pp. 8-47. 


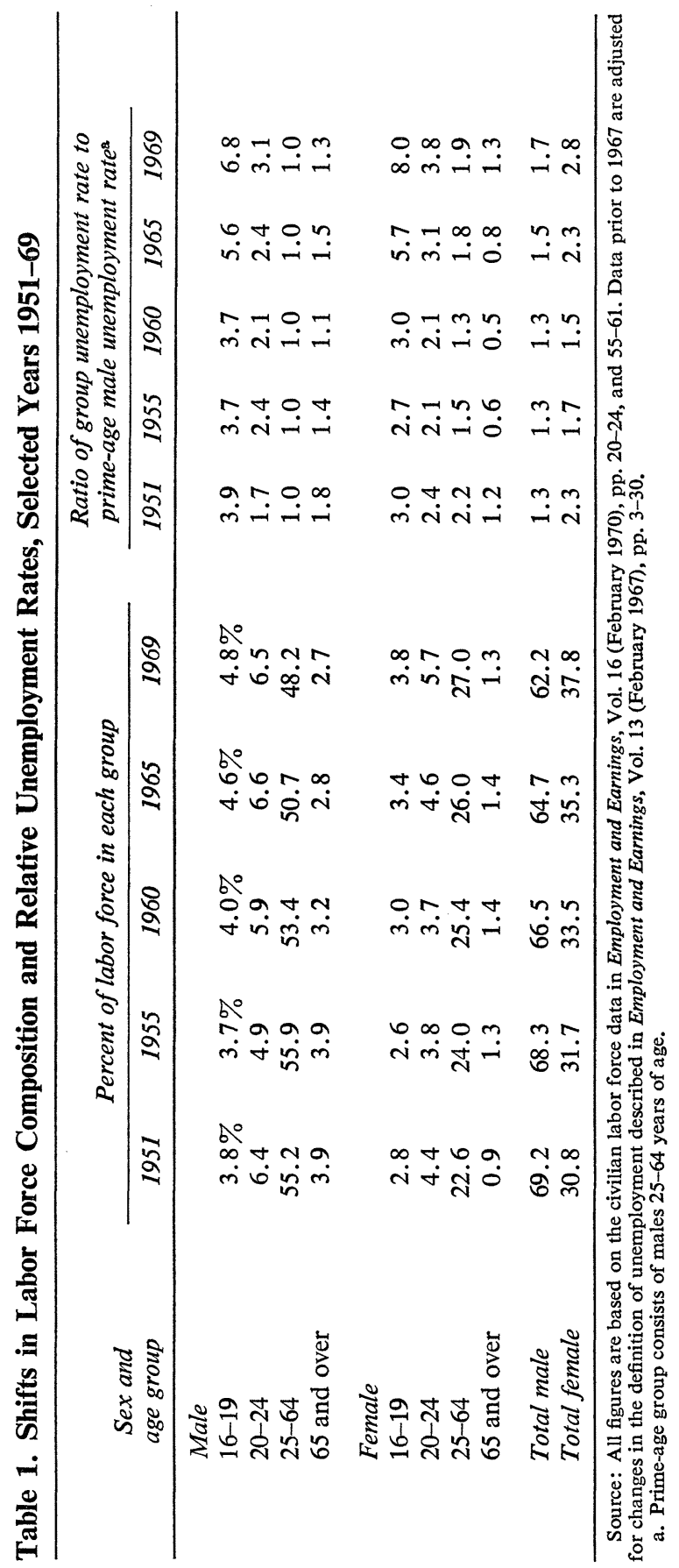


unemployment rate ratio deteriorated for all other groups during the 1960s, and for all but men over 65 years between 1955 and 1969. But by far the worst deterioration has been in the relative unemployment rates of young workers.

\section{A WEIGHTED UNEMPLOYMENT RATE}

If all individuals offered closely similar supplies of labor, an aggregate unemployment measure could serve despite the changing size and unemployment experience shown in Table 1. But large and persistent differences exist in the labor supply offered by individuals in the several age-sex groups. $^{3}$

For one thing, some individuals work more hours on the average than others. In large part because of the difference in the proportion of parttime workers and workers holding more than one job, on average prime-age men work more hours per week than prime-age women, while younger and older persons work fewer hours on average than the prime-age workers of either sex. On the reasonable assumption that the unemployed in each age-sex group are offering an average number of hours of work similar to that provided by their employed counterparts, the correct relation between the labor input offered and the number of individuals unemployed varies according to the age-sex composition of the unemployed.

A similar adjustment is needed to account for the fact that average wages vary systematically among age-sex groups. If a similar rate of wage increase for all workers is associated with any given degree of labor market tightness, then weighting groups by their relative wage levels is necessary in a model explaining the change in average wages: A 10 percent change in the wage of workers earning $\$ 2.00$ per hour will have only half the effect on the aggregate wage average as will the same percentage change in the wage of a worker earning $\$ 4.00$ per hour. A second way of looking at this kind of adjustment is to view wage differences as a proxy for productivity differences. If the force of an unemployed worker on labor market tightness is measured by what he would contribute to production if employed, then again weighting by relative wages is called for.

Combining the adjustments for average hours and average wages just

3. Edward F. Denison kindly gave me access to his worksheets on these differences, prepared for another purpose. The weighting index discussed here is based on his data. 
discussed leads to the index for weighting individuals according to their age-sex group. ${ }^{4}$ And adding up the weighted labor force and weighted unemployment permits the calculation of a weighted unemployment rate. The effect of weighting is not canceled in computing this new unemployment rate concept since the relative importance of each of the various agesex groups is not the same in employment and unemployment. For the most part, the groups with high unemployment also have low values for the weighting index, indicating that, relative to the average employee, they earn lower wages or work fewer hours or both.

Compared with the official unemployment rate, the weighted unemployment rate gives a picture of a progressively tighter labor market in recent years relative to earlier periods. The spread between the official and weighted unemployment rates has widened from less than half a point in the early 1950 s to a full point in the late 1960s. Earlier research suggests that the inverse of unemployment rates is the preferred form for measuring labor market tightness, and it is the form used here. ${ }^{5}$ Figure 1 shows the inverse of the weighted unemployment rate for the postwar period, expressed as an index with 1956 equal to 100 , and compares it with a similar index based on the official unemployment rate and with other indicators of labor market tightness discussed below.

\section{UNEMPLOYMENT DISPERSION}

The weighted unemployment rate scales different members of the labor force more appropriately, but still treats all workers as perfect substitutes. It recognizes the difference between one pint and one quart of an input, which the official unemployment rate does not; but it still treats the input as homogeneous, making two pints a perfect substitute for one quart. If labor force groups are in fact imperfect substitutes for one another, one should expect to find unemployment differentials among groups varying over time; and accounting for the changing dispersion of unemployment should lead to a better measure of labor market tightness. The formal conditions under which the economy with more dispersed unemployment rates will be more inflationary, given the average unemployment rate, have

4. The weights used are given in the appendix.

5. George L. Perry, Unemployment, Money Wage Rates, and Inflation (M.I.T. Press, 1966), p. 55. 


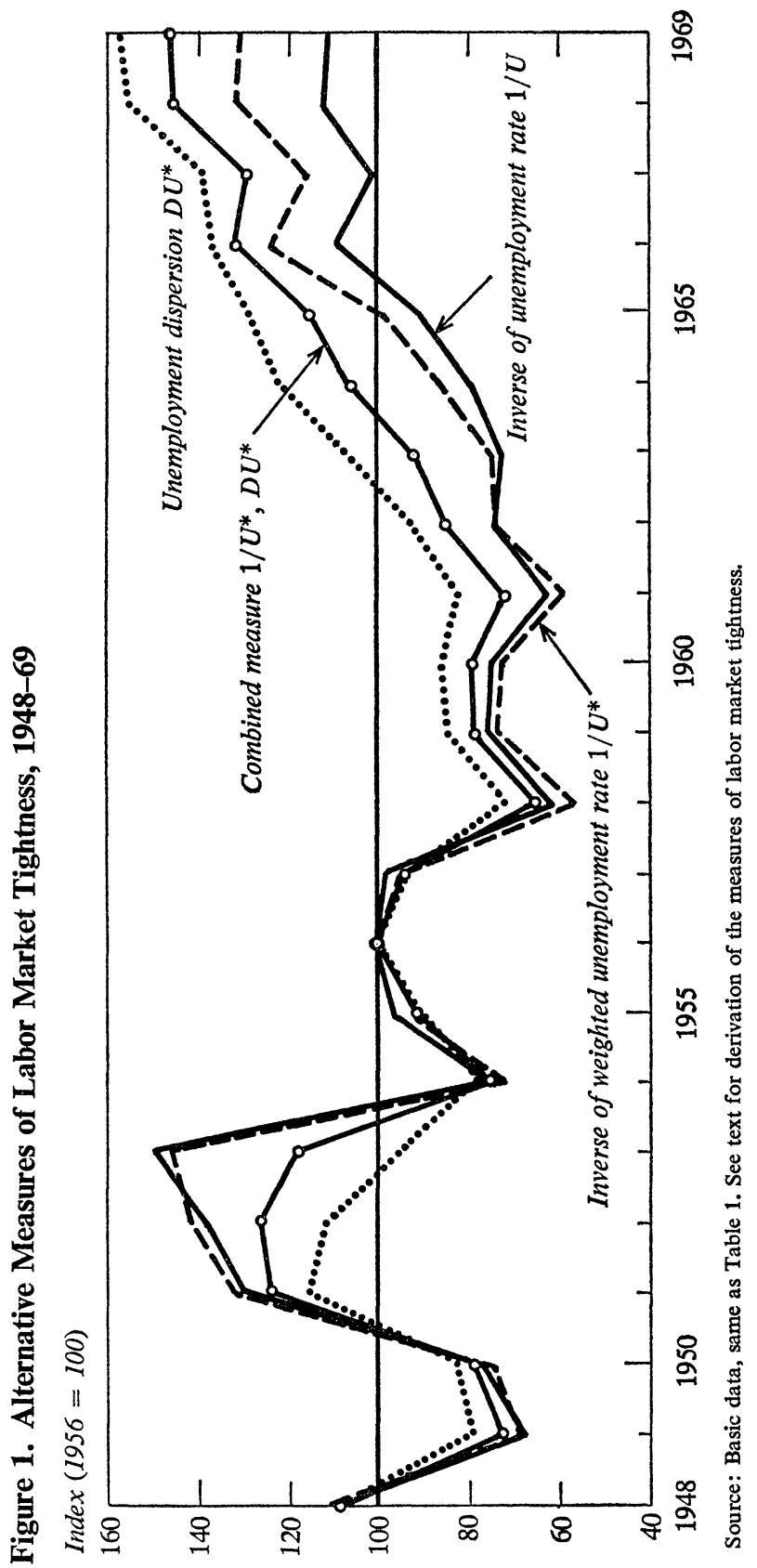


been presented elsewhere. ${ }^{6}$ But a host of practical problems arises in attempts to formulate a proper measure of dispersion for empirical testing.

One problem comes in choosing useful ways to segment the overall labor market from available data. Statistics of varying quality and reliability are available for employment and unemployment by geographic regions, by occupational categories, by industry of last employment, and by age-sex and white-nonwhite groupings; the historical dispersion of unemployment by these classifications has been discussed by Gordon. ${ }^{7}$ Because the imperfection of substitution among categories may be small in some of these cases, they are not equally good candidates for amending the average unemployment rate. For instance, individuals change the occupations and industries in which they work quite easily. Some research has been done introducing geographic measures of dispersion to supplement average unemployment in a model explaining inflation, and this work shows that greater dispersion is associated with more inflation for a given average unemployment rate. ${ }^{8}$ On the other hand, Robert Hall, in his article in this issue, suggests that most of the observed differences in unemployment among labor market areas in periods of full employment are characteristic of these areas, and that overall labor market tightness would not be substantially improved by attempts to equalize the geographic unemployment differentials that are observed.

I have focused on the dispersion of unemployment among the age-sex groups of the labor force because the growing disparities in group unemployment rates shown in Table 1 suggest that substitution among them is quite imperfect. The best mathematical form for a dispersion measure cannot be specified without more knowledge than is now available about how individual labor markets interact and affect wages. I chose to measure dispersion as the sum over all age-sex groups of the absolute difference between each group's share of total weighted unemployment and its share of the total weighted labor force. ${ }^{9}$ This gives a dispersion measure that complements the weighted unemployment rate appropriately for all the

6. G. C. Archibald, "The Phillips Curve and the Distribution of Unemployment," in American Economic Association, Papers and Proceedings of the Eighty-first Annual Meeting, 1968 (American Economic Review, Vol. 59, May 1969), pp. 124-34.

7. Robert A. Gordon, The Goal of Full Employment (John Wiley, 1967), pp. 91-116.

8. Archibald, "The Phillips Curve."

9. Gordon has used the same mathematical form for measuring dispersion in Goal of Full Employment. 
cases of changing relative labor force sizes and changing relative unemployment rates that $I$ have thought about.

I tried several ways of adjusting the group unemployment rates, all of them designed to estimate, and then to eliminate from the dispersion measure, the "normal" differences in unemployment rates among groups. None of these attempts produced a dispersion measure that helped explain wage changes, while the use of unemployment rates without adjustment for normal differences produced a successful dispersion measure. Probably the most important reason for this rather surprising outcome is the inadequacy of the data. The quarterly unemployment data by age-sex groups are not completely accurate. Adjusting them to eliminate normal unemployment differences among the groups enlarges the relative importance of the errors, and the dispersion of these adjusted data becomes meaningless. The dispersion measure using unadjusted unemployment rates succeeds because the relative unemployment differentials widened steadily during the period, rather than oscillating. Thus, although the true dispersion of labor market tightness throughout the period may have been smaller than the dispersion of unemployment rates indicated, this error was largely a matter of scale; apparently true dispersion grew as the dispersion of unempioyment rates grew, which is what matters.

The dispersion measure, designated $D U^{*}$, is shown in Figure 1, expressed as an index with 1956 equal to 100 . In recent years, dispersion has been greater than at any previous time for which the series was computed, despite lower average weighted and official unemployment rates in some earlier years. And it has grown steadily every year from 1961 to 1969.

\section{A COMBINED MEASURE}

Weighted unemployment and its dispersion, used together, provide another measure of labor market tightness. In order to compare it with other measures in Figure 1, the two were combined using as weights their coefficients in an equation explaining wage changes, and the variable thus formed was expressed as an index with 1956 equal to 100 . The equation itself is discussed extensively below.

The combined measure reveals that labor markets were tighter in 1968 and 1969 than in any previous year. By comparison, in these same years, the measure using the conventional unemployment rate alone was substantially below Korean war levels. 


\section{HIDDEN UNEMPLOYMENT}

Many factors govern what fraction of the working-age population will be in the labor force at any time. The age-sex composition of the population is important because labor force participation rates vary systematically among the age-sex groups. Over much of the postwar period, participation rates of individual groups have changed gradually. In addition, the participation rates of some groups are cyclically sensitive, with the fraction of workers in the labor force larger when unemployment rates are low than when they are high. Thus with less than full employment, some potential workers do not enter the labor force and are not counted as unemployed. These are the hidden unemployed.

I have estimated hidden unemployment over time using a model similar to Simler and Tella's, which makes participation rates for individual age-sex groups depend on a time trend and the current unemployment rate. ${ }^{10}$ But for the reasons given earlier, I have weighted hidden unemployment in the same way as regular unemployment. Hidden unemployment grows in the late 1950s and early 1960s, then declines sharply, reaching negative values in the last years of the decade. This pattern arises for two reasons: (1) The relative importance in the population of those age-sex groups exhibiting cyclically sensitive participation rates changes, as it did with the expansion of the young age groups after the mid-1950s; and (2) in recent years, when the numbers of women and young persons in the labor force grew rapidly, actual participation rate experience deviated substantially from a prediction based on current unemployment rates alone.

While the concept of hidden unemployment is itself well established for purposes such as projecting the potential output of the economy, its place in explaining wage changes is less clear. It is tried along with the other measures of labor tightness to test whether those not actively seeking work should play a role comparable to the unemployed in a model explaining wage changes.

\section{The Model of Wage Changes}

The labor market concepts just discussed are used as part of a model explaining wage changes. The parameters of the model are estimated from

10. Simler and Tella, "Labor Reserves." 
quarterly data for the period from 1953:1 to 1968:4. There were two reasons for starting the period in 1953. First, some of the disaggregated data needed to construct the different measures of labor market tightness are less reliable in the early postwar years. Second, I suspect that the years before 1953 were dominated by events that cannot be adequately represented in the basic model of wage changes used here. The immediate postwar years saw prices and wages rising rapidly and adjusting to the disequilibrium created by World War II and wartime controls. Then, not long after these effects were over, the outbreak of the Korean war brought first a rapid runup in both prices and wages and then a period of controls starting in early 1951 . While econometric work done some years ago had to include these periods because interesting observations were then so scarce, it now seems better to omit them. The sixteen years of observations available from 1953 to 1968 include abundant periods of cyclical downturns, high and low unemployment, and the inflations of the mid-1950s and the late 1960s. To add years before 1953 to this sample seems to yield more noise than information. The observations after 1968 are used to test the forecasting ability of equations estimated through 1968. Changes in compensation per manhour during 1969 were rather puzzling and would have altered some of the estimates. I shall discuss this below. But since the data for 1969 and 1970 are preliminary and subject to revision, it seemed better to base the main analysis on the data through 1968.

The basic change variables in the model, such as changes in wages or prices, are used as percentage changes over four quarters in order to reduce the importance of inaccuracies in the basic data that would be prominent if one-quarter changes were used. Correspondingly, variables used as levels, such as unemployment and other measures of labor market tightness, enter the model as moving averages over four quarters of observations, including the current quarter and three preceding ones. For several variables whose specification is somewhat complex, a fuller description is offered in the appendix.

\section{UNEMPLOYMENT RATE}

The official aggregate unemployment rate $U$ is one measure of labor market tightness and is used here with only minor adjustments: The historical data are adjusted for the changes in the definition of unemployment introduced in 1967 so that all observations are on the basis of the new 
definitions. Also, the numbers in the armed forces are added to both employment and the labor force, and 14- and 15-year-olds are added to the data, two changes that largely offset each other in their effect on the aggregate unemployment rate. This unemployment variable is used in the form $1 / U$.

\section{WEIGHTED UNEMPLOYMENT}

The weighted unemployment rate $U^{*}$ is formed from the previous variable $U$ by disaggregating both the number unemployed and the number in the labor force into age-sex groups, multiplying the number of individuals in each group by the index discussed earlier, and summing the weighted unemployment and weighted labor force groups to form the weighted unemployment rate variable. It is used in the form $1 / U^{*}$.

\section{UNEMPLOYMENT DISPERSION}

The variable for unemployment dispersion $D U^{*}$ is formed thus:

$$
D U^{*}=\operatorname{sum} \text { of }\left|\frac{V_{i}^{*}}{V^{*}}-\frac{L_{i}^{*}}{L^{*}}\right|
$$

where $V_{i}^{*}$ and $L_{i}^{*}$ are, respectively, the number of unemployed and the number in the labor force in an age-sex group weighted as before, $V^{*}$ and $L^{*}$ are the corresponding totals, and the sum is taken over all age-sex groups. $D U^{*}$ can also be expressed in terms of unemployment rates:

$$
D U^{*}=\operatorname{sum} \text { of } \frac{L_{i}^{*}}{L^{*}}\left|\frac{U_{i}^{*}-U^{*}}{U^{*}}\right|
$$

where $U_{i}^{*}$ and $U^{*}$ are the group and total weighted unemployment rates.

\section{HIDDEN UNEMPLOYMENT}

Weighted hidden unemployment is based on an estimate of the number of persons who would have been in the labor force had the actual unemployment rate been 3 percent rather than its actual value in any quarter. The estimated number of hidden unemployed are weighted as above and divided by the weighted labor force to get $H U^{*}$, the hidden unemployment rate used in the model. 


\section{TOTAL COMPENSATION PER MANHOUR}

For the basic wage variable to be explained by the model, I use the percentage change over four quarters in compensation per manhour in the private nonfarm sector of the economy, designated $w$, with two adjustments. The first accounts for the effect on average compensation of changes in the age-sex composition of employment. Because hourly earnings differ among these age-sex groups, a change in the relative composition of total employment changes average compensation even if no individual's hourly compensation changes. My adjustment uses the weighting factors discussed above to remove this effect of relative employment shifts among age-sex groups from $w$. The second adjustment removes the effects of overtime pay and of interindustry shifts in employment, using factors developed by Robert J. Gordon. ${ }^{11}$ The two adjustments may overlap somewhat; but a regression test explaining $w$ indicated that the two should be used together. The dependent variable in the wage equations, designated $w^{*}$, is thus $w$ corrected by both adjustments.

\section{LIVING COSTS}

Most recent studies of the determinants of wage changes try to allow for the effect on wages of living costs, as measured by the consumer price index (CPI). I use, alternatively, two measures of living costs in the wage equation: the four-quarter percentage change in the index $p$, and the longer distributed lag on changes in the CPI developed by R. J. Gordon as a proxy for expected price changes, designated $p^{*} .{ }^{12}$

\section{SECONDARY EMPLOYMENT CHANGES}

One characteristic of tight labor markets that may not be fully reflected in the unemployment and dispersion variables is the tendency of employers to hire more secondary workers in such circumstances. The percentage change over four quarters in the employment of prime-age female workers is tried as an additional explanatory variable to capture such effects. The variable is designated $f e$.

11. R. J. Gordon, "Problems in Predicting the Rate of Inflation" (paper presented at the North American Regional Conference of the Econometric Society, New York, December 1969).

12. Ibid. 


\section{WAGE-PRICE GUIDEPOSTS}

A dummy variable $G$ is introduced to capture the effects of the wageprice guidepost period. The guideposts are assumed to have been administered with equal force from 1962:2 through 1966:4, and to have been inoperative in other quarters.

\section{SOCIAL INSURANCE CONTRIBUTIONS}

Because the compensation data include nonvoluntary employers' contributions for social insurance, a variable measuring the impact of these contributions on $w^{*}$ is used in the estimation. It is designated $c$.

\section{Econometric Estimates of Wage Changes}

Table 2 shows regression results for the basic wage change model using the variables just described. Most of the equations in the table compare the accuracy of the various measures of labor market tightness in explaining wage changes. ${ }^{13}$

\section{THE WEIGHTED UNEMPLOYMENT RATE}

Equations (1) and (2) compare the weighted unemployment rate with the conventional unemployment rate as measures of labor market tightness in the basic wage model. The weighted unemployment rate does better. The higher $\bar{R}_{u}^{2}$ in equation (2) indicates that substituting weighted unemployment for official unemployment explains 17 percent of the variance in wage changes left unexplained by equation (1). In addition, the coefficient on weighted unemployment has a slightly larger ratio to its standard error than the coefficient on official unemployment does. These statistical differences support my a priori judgment that the weighted unemployment rate

13. All equations were estimated using an adjustment for first-order serial correlation in the residuals, shown as $r$ in Table 2. The summary statistics shown for each equationthe proportion of variance explained $\bar{R}_{u}^{2}$, and the standard error of estimate $S E_{u}$-are computed directly from the coefficient estimates, without using the serial correlation correction. This permits a better comparison of the alternative measures of labor market tightness on the basis of the summary statistics. 


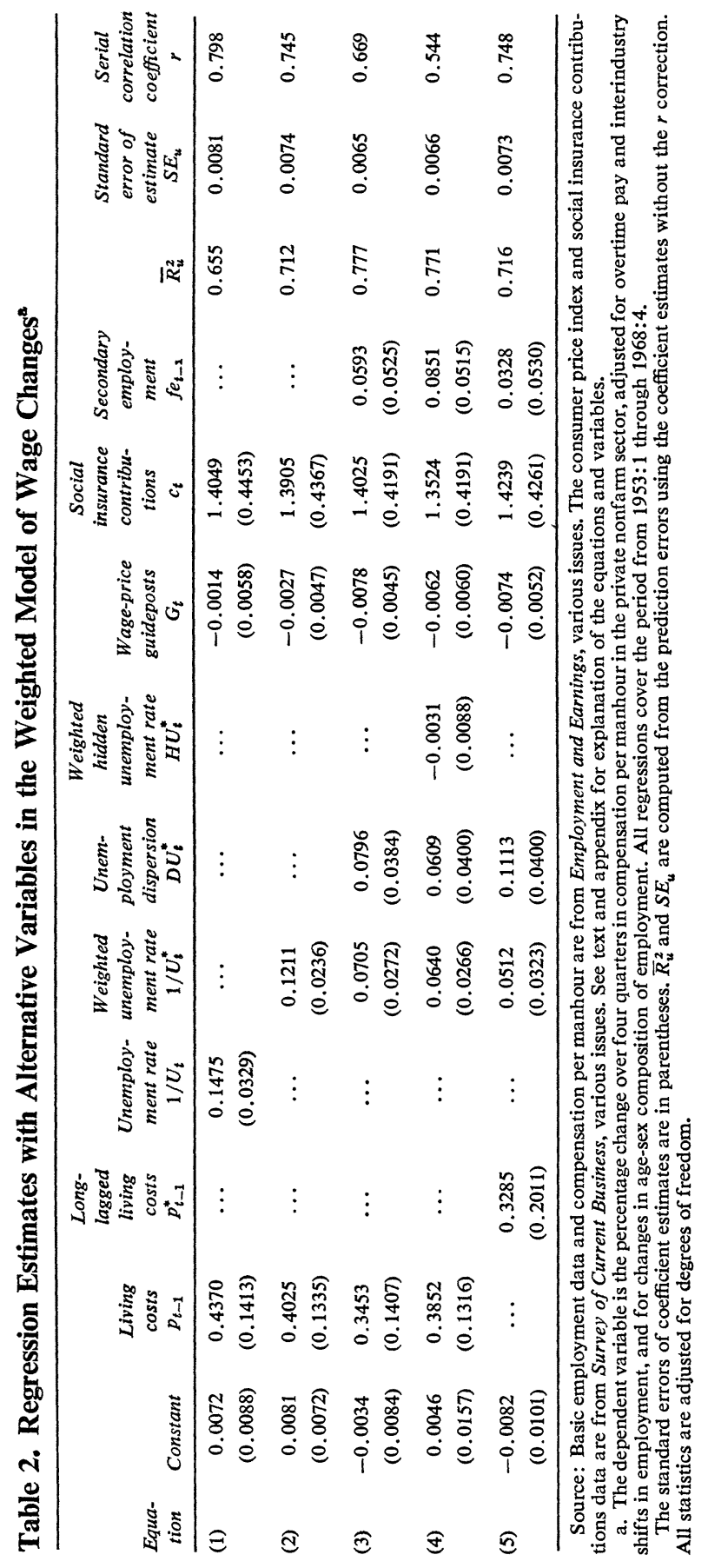


was the better variable for explaining average wage changes because it differentiates usefully among the members of the work force.

\section{UNEMPLOYMENT DISPERSION}

Equation (3) introduces the variables measuring unemployment dispersion and the lagged change in secondary employment. It gives the best statistical fit of any equation, explaining 35 percent of the variance that was left unexplained by equation (1). ${ }^{14}$ All the improvement in fit over equation (2) comes from the dispersion variable. I include the lagged employment change variable because it reduces the errors in 1956 slightly and because it keeps the coefficient on prices nearer to that reported by other studies: Without it, the coefficient on prices drops to 0.27 .

The addition of the dispersion variable reduces the coefficients on both prices and the unemployment variable, while raising the estimated impact of the wage-price guideposts. This equation, using both weighted unemployment and its dispersion to measure labor market tightness, is my choice on a priori grounds as well as for its statistical fit. The combination of unemployment and dispersion plotted in Figure 1 is based on the coefficients of the two variables in this equation. And the subsequent discussion of the inflation problem stems from it.

\section{HIDDEN UNEMPLOYMENT}

Equation (4) explores the importance of the hidden unemployment concept for analyzing inflation by adding the variable for weighted hidden unemployment to the preferred equation. The coefficient of the new variable has the negative sign expected of it, but is only one-third the size of its

14. The summary statistics still probably understate the improvement over equation (1) that comes from using the better measures of labor market tightness. Price changes are included as an explanatory variable in the equations, and wage changes largely determine price changes. Thus if the official unemployment rate understates labor market tightness in recent years, the coefficient estimated on prices is likely to be higher to compensate for this misspecification on the labor market variable. This will reduce the difference in $\bar{R}^{2}$ s between the equations. In fact, the progressive improvement in $\bar{R}^{2}$ in equations (1), (2), and (3) when the price term is omitted is much greater than the improvement shown in Table 2: The respective $\bar{R}^{2}$ s go from 0.374 to 0.523 to 0.698 for equations estimated without the serial correlation adjustment and without a price term as an independent variable. 
standard error. And the explanatory power of the whole equation, adjusting for the fact that an additional explanatory variable is used, actually declines, as indicated by the lower $\bar{R}_{u}^{2}$ in equation (4). Hidden unemployment, as measured here with weighted labor force variables, does not seem to have any influence on wage changes. This is not surprising, since it is quite plausible that potential entrants to the work force exert nothing like the same downward pressure on wages that is exerted by unemployed workers who are actively seeking jobs.

A statistical problem arises in testing for the comparative importance of hidden unemployment and guideposts since, as the employment situation actually developed, the presumed depressing effect of hidden unemployment on wage changes was greatest during the period when guideposts were being actively used. The technique of separating hidden unemployment from measured unemployment used here is a better test than can be achieved by combining the two into a variable for total unemployment; doing the latter forces the same coefficient on hidden and normal unemployment, leaving little to be explained by the guideposts.

\section{LIVING COSTS}

Equation (5) uses the same labor market variables as equation (3) but substitutes Gordon's living cost variable with its long lags for the rate of change of living costs over four quarters. The coefficient estimated for living costs is virtually identical, despite its considerably different lag structure. Compared with equation (3), equation (5) assigns more importance to dispersion and less to weighted unemployment. Since I have reservations about how accurately the former variable captures dispersion effects, I prefer to analyze on the basis of equation (3), which gives it slightly less importance. Equation (3) also sharpens the coefficient estimates of the other explanatory variables, because it relies on a smaller autoregressive correction and generally fits the data better, as shown by its high $\bar{R}_{u}^{2}$.

The coefficient on price changes in equation (3) indicates that 35 percent of a change in living costs is translated into a subsequent change in wages. It may be assumed that, given enough time, prices will rise by the full excess of wage changes over the trend growth in productivity, taken to be 2.7 percent a year. If these estimates of the interaction between prices and wages are combined, eventually the difference in the rate of wage increase between two alternative, permanent states of labor market tightness will 
be about 1.5 times the immediate difference estimated from the labor market coefficients in equation (3). On the basis of this estimate, therefore, after a tightening of labor markets, wages and prices would rise 1.5 times faster in the long run than in the short run; but the rate of increase would not display the indefinite rise the accelerationist models would predict.

The present research is not aimed at a thorough test of the accelerationist hypothesis; it concentrates instead on developing improved measures of labor market tightness. The accelerationist view would presumably require that prices influence wages in an irregular way, with their impact growing larger as any inflationary condition persisted through time. By contrast, the price coefficient in equation (3) must be understood as an average that best fits the data for the entire sample period. But while the regression estimates do not offer a test, a discussion of recent wage changes presented below does offer evidence against the accelerationist hypothesis.

\section{WAGE-PRICE GUIDEPOSTS}

In both equations that use the combined measure of labor market tightness that I prefer, the wage-price guideposts are estimated directly to have reduced the rate of wage increase by about three-quarters of a percentage point. Allowing for the impact on prices of this much wage restraint, and the impact back on wage changes from lower prices, this implies about a 1.2 percentage point reduction in the rate of inflation, 1.5 times the direct effect.

\section{SOCIAL INSURANCE CONTRIBUTIONS}

The variable accounting for employers' contributions for social insurance has a coefficient of about 1.4 in all the equations. Since there is a corresponding change in employees' contributions, the simplest way to look at the estimate of 1.4 is that approximately 40 percent of the increase in employees' contributions is passed on to employers in the short run in the form of higher wages.

It should be emphasized that this estimate contains no information about the real burden of the social insurance tax, which is the primary concern of tax incidence theory. The real burden would depend on the effect on prices of both the employers' tax and the portion of the employees' tax that is passed forward through higher wages. 


\section{Recent Wage Changes}

The model represented by equation (3) provides a good explanation of wage developments during the inflationary period from 1966 through 1968. As shown in Table 3, the errors are generally small and the equation does not persistently underpredict or overpredict actual wage changes during these twelve quarters. This is also true for the first three quarters of 1970 on the basis of preliminary data.

In 1969, however, the model overpredicts wage changes by an average of 0.9 percentage point. Part of the puzzle is in the behavior of actual wages. Wage changes slowed by 0.21 percentage point between 1968 and 1969. Allowing for the predicted effect of the increase in social insurance contributions that took place, the slowdown was 0.33 percentage point.

\section{Table 3. Actual and Predicted Wage Changes, 1966-70}

Percentage changes over four quarters

\begin{tabular}{cccc}
\hline Year and quarter & Actual & Predicted & Error \\
\hline Regression period & & & \\
19661 & 5.84 & 5.71 & 0.13 \\
2 & 6.30 & 6.32 & -0.02 \\
3 & 6.50 & 6.66 & -0.16 \\
4 & 7.07 & 7.08 & -0.01 \\
19671 & 6.65 & 6.62 & 0.03 \\
2 & 6.38 & 6.58 & -0.20 \\
3 & 6.45 & 6.54 & -0.08 \\
4 & 6.01 & 6.74 & -0.73 \\
19681 & 7.30 & 6.48 & 0.82 \\
2 & 7.28 & 7.80 & -0.51 \\
3 & 7.51 & 7.77 & -0.26 \\
4 & 8.24 & 7.84 & 0.41 \\
Forecast period & & & \\
1969 & & & \\
2 & 7.22 & 8.84 & -1.62 \\
3 & 7.32 & 7.62 & -0.30 \\
4 & 7.54 & 8.61 & -1.07 \\
19701 & 7.41 & 8.15 & -0.74 \\
2 & 7.29 & 7.90 & -0.61 \\
3 & 7.57 & 7.74 & -0.17 \\
& 7.99 & 7.72 & 0.27 \\
\hline
\end{tabular}

Sources: Actual-see Table 2, source and note $a$; predicted-derived from equation (3), using autocorrelation adjustment (see text). 
At the same time, rising prices and some further tightening of labor markets led to a predicted wage speedup of 0.88 percentage point, more than half of which was due to prices. Thus, ignoring the autocorrelation adjustment, from 1968 to 1969 a 1.2 percentage point spread opened up between actual and predicted wage changes.

It is hard to think of any model, based on any view of the inflation process, that would not predict some speedup of wage changes during 1969. All the measures of labor market tightness, including the official unemployment rate, point to slightly tighter labor markets over the relevant quarters, while any view of the inflation process stressing the importance of recent price changes calls for a substantial acceleration in wages in 1969.

The adjustment for the changing age-sex employment mix that was made to the official compensation data was important in 1969. Without it, the slowdown in wage changes, instead of measuring 0.20 percentage point, would have been 0.55 percentage point. Furthermore, with this adjustment and the Gordon adjustment for industry shifts and overtime, which becomes substantial in 1970, there is no sign of any slowdown in wage changes through 1970:3. The Gordon adjustments for 1970 are my own, estimated in a highly simplified way, so not too much should be made of the figures for 1970 until Gordon's detailed calculations are updated. My estimates of the adjustment for the first three quarters of 1970 add $0.25,0.42$, and 0.49 percentage point to the percentage wage increase from four quarters earlier, very nearly the same adjustments Gordon estimates for the first three quarters of 1960, the start of the 1960-61 recession.

\section{THE ACCELERATIONIST THEORY}

The prediction errors for the whole of the current inflationary period offer evidence against the accelerationist view of the inflationary process. On this view, once labor markets become tight enough to start inflationary wage increases, wages and prices will accelerate indefinitely. Thus a given inflationary unemployment rate will be associated with ever faster rates of wage and price increases the longer it is maintained.

If this view were relevant in an inflationary period like the late $1960 \mathrm{~s}$, as the period continued, labor markets remained tight, and inflationary expectations became more widespread, one would have expected actual wage increases to have outrun predicted wage increases by increasing amounts. Yet, if anything, exactly the opposite happened, with the equation generally 
overpredicting wage changes for the last part of the period after predicting accurately at the start of the inflation. The same point is made if 1969 is added to the period used in estimating the wage equation. Rather than increasing the price coefficient in the wage equation, the addition of 1969 to the estimation period reduces it sharply-from 0.35 to 0.27 . At the same time the coefficient estimate on dispersion falls to 0.056 , while that on weighted unemployment rises slightly to 0.077 . So adding the 1969 experience disrupts all coefficient estimates to some extent; but most noticeably, the results run counter to what one would expect from the accelerationist view.

These conjectures from recent developments are necessarily tentative. What happens in 1971 could alter the impact of the evidence. And in any case, these estimates fall well short of formally testing the accelerationist theory. But they do constitute interesting evidence on an important issue that can be summarized simply. In recent years, wages have risen faster than predicted by an equation such as (1), based on the official unemployment rate. But the errors characterize the period of the last few years as a whole, and are adequately corrected by improving the measure of labor market tightness, as equation (3) does. They do not grow persistently or abruptly larger as the period progresses, as the accelerationist view would predict. If this view has applicability, it would appear to be for a different, perhaps more intensely inflationary environment than the one we have been experiencing.

\section{The Worsening Trade-off}

The new measure of labor market tightness developed here has some striking implications for the trade-off between inflation and unemployment. As it is conventionally conceived, the trade-off has worsened. Figure 2 illustrates how much it has worsened since the mid-1950s on the basis of estimates using the combined measure of labor market tightness.

The figure illustrates a steady-state trade-off in which any given unemployment rate has persisted long enough for the price-wage interactions to stabilize. This process was discussed in connection with the coefficient of living costs in the wage equation.

The figure is based on the official concept of compensation per manhour. I assume that the employment mix adjustment makes $w$, this measure of 
Figure 2. The Shift in the Trade-off between Inflation and Unemployment Annual wage increase Annual price increase (percent) (percent)

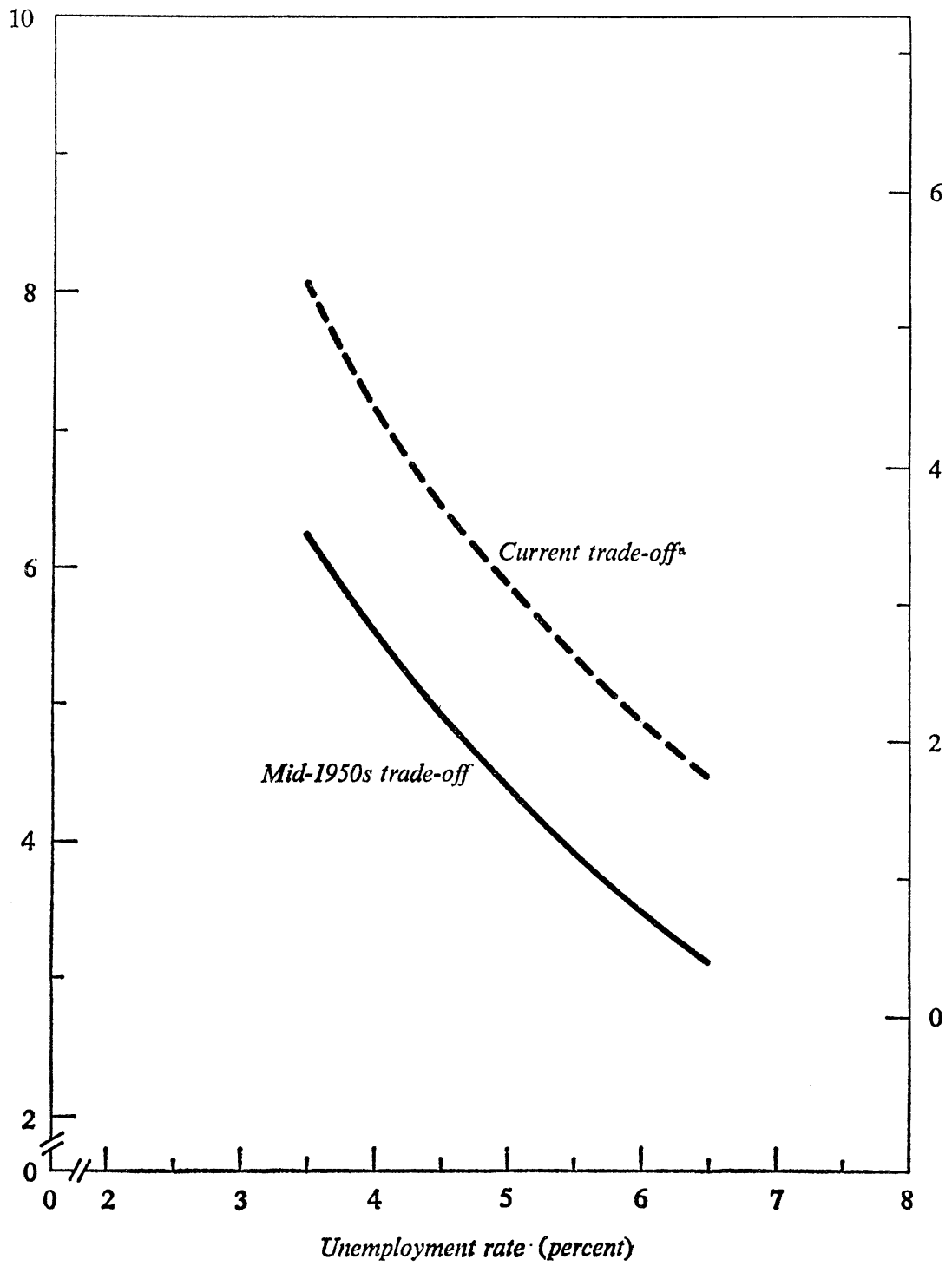

Source: Based on equation (3) and adjustments (see text). See Table 2 for sources for basic data. a. Based on 1967-70 experience. 
wage change, rise 0.26 percentage point (the 1953-68 average value of the adjustment) slower than $w^{*}$, the adjusted measure used in the regressions. The Gordon adjustment is trendless and requires no correction for the steady-state calculations made here.

The difference between the trade-off for the mid-1950s and the current trade-off, illustrated in Figure 2, results from the changed relation between the official unemployment rate and the combined measure of labor market tightness in the two periods. In the figure, at 4.0 percent unemployment, the annual rate of inflation is estimated to be 1.7 percentage points higher today than it would have been in the economy of the mid-1950s-4.5 percent rather than 2.8 percent. This shift in the curve allows for the prediction errors from equation (3) for the two periods. For 1956-57, the equation underestimated wage changes by 0.30 percentage point and for 1968-70 it overestimated by 0.34 percentage point. Allowing for the interactions between wages and prices, I shifted the curve for the 1950 s up by 0.5 percentage point and the current curve down by the same amount in constructing Figure 2.

Since Figure 2 relates wage changes to the official unemployment rate, while equation (3) is based on the combined measure of labor market tightness, the expected relation between this rate and this measure is used in constructing each of the trade-off curves shown. This expected relation takes demographic conditions as fixed and thus applies to the trade-off curve in any one period. It does not describe the secular change in the relation that has been observed and that lies behind the shift in the curve illustrated in the figure. Historically, at a given point in time, a 1 percentage point difference in the official unemployment rate has been associated with an estimated difference of 0.94 percentage point in the same direction in the weighted unemployment rate and a change of 0.036 in the opposite direction in the dispersion index. Each of the curves of Figure 2 is based on these relations used together with equation (3).

\section{CHANGING LABOR MARKETS}

The trade-off curves in Figure 2 are different because at the same official unemployment rate, the labor market is tighter today than it was in the mid-1950s. The change that has occurred in labor markets to cause this can be decomposed into two parts: A change in the proportion of workers in the several age-sex groups; and a change in the relative unemployment 


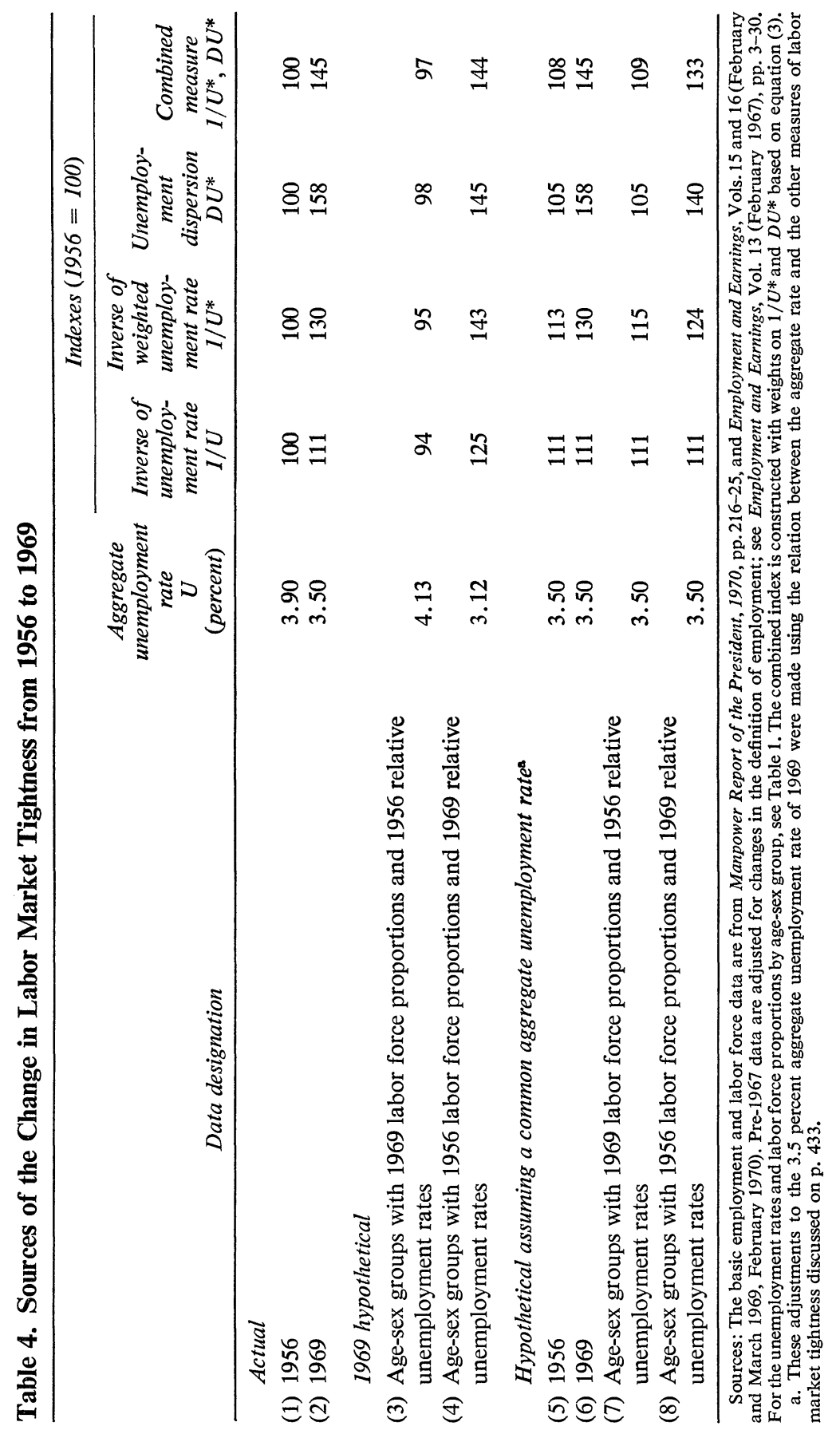


rates of these groups. In Table 4, the results of this decomposition are shown for the changes that occurred between 1956 and 1969.

The third and fourth rows of the table show the effects of two kinds of adjustments. First, given the actual labor force composition that prevailed in 1969, if the average unemployment rate in each age-sex group had been the same as it was in 1956, labor markets would have had the characteristics shown in row (3). Second, labor markets would have had the characteristics shown in row (4) if the 1956 labor force composition had been associated with the 1969 group unemployment rates. These hypothetical changes result in changes in the average unemployment rate, as well as in the other measures of labor market tightness developed here.

In order to make a direct comparison among the four states of the world depicted in rows (1) through (4), they can be reduced to a common unemployment rate-the 3.5 percent of $1969 .{ }^{15}$ The results are reported in the second half of the table. With this adjustment, the difference between rows (5) and (6) shows convincingly that the changes in relative unemployment rates, or in labor force composition, or in both, made 1969 labor markets tighter than those in 1956 at the same aggregate unemployment rate. In a comparison of row (5) with row (7), the shift in relative unemployment rates is singled out as the main source of this deterioration, for, if the 1956 relative unemployment rates had prevailed-as row (7) depictslabor market tightness would have been virtually the same in 1969 as in 1956, despite the large increases in the number of secondary workers.

Although it is primarily the widening divergence of unemployment rates that has worsened the trade-off, this widening is itself related to the changing composition of the labor force. As Table 1 shows, as the relative size of an age-sex group has grown, its relative unemployment rate has generally worsened. The effect of this has been most dramatic in the young age groups. But it has also been true for prime-age women relative to men. As the relative number of prime-age men has diminished, employers have pushed the already low unemployment rate of this group even lower rather than expanding further the employment of other workers.

A good deal of substitution in employment across age-sex groups has been taking place, but it has not been sufficient to keep unemployment rates from diverging. The proportion of jobs held by workers in the differ-

15. These adjustments were made using the relation between the aggregate rate of unemployment and the other measures of labor market tightness discussed on p. 433. 
ent age-sex groups has nearly kept pace with the changing proportion of workers in each group. In 1956, for instance, 15 percent of those employed were under 25 years old. In 1969, this age group accounted for 20 percent of the employed. Still, 50 percent of all the unemployed were under age 25 in 1969, compared with 31 percent in 1956. In order to reproduce, in 1969, the 1956 pattern of relative unemployment rates, nearly one-half million jobs would have had to be shifted from prime-age workers to young workers, three-fourths of them from prime-age men.

\section{OTHER FORCES AFFECTING THE TRADE-OFF}

One main reservation to all this is whether the age-sex groupings used here have failed to capture other forces that have been at work improving the trade-off. If the labor force had been standardized on lines other than age-sex groups, the change in the trade-off might have looked quite different. If educational achievement had been used, for instance, an improving trade-off could have appeared. It is impossible to test this proposition convincingly. I did, however, add a time trend to the model. If factors such as improving average education had pushed in the direction of improving the trade-off, the time trend might have captured their effect. The time trend took on a small negative value, but its coefficient was considerably smaller than its standard error. Introducing it into the equation also raised the coefficient of the dispersion variable so that there was no net change in the estimated deterioration of the trade-off.

\section{Future Wage Changes and Inflation}

It would be inappropriate to offer a detailed inflation forecast for the near future without a model more complete than the one developed here. In particular, the short-run influence of wage changes and other factors on prices has not been analyzed. In 1967, 1969, and thus far in 1970, the private nonfarm deflator rose 3.1 or 3.2 percentage points less than the wage series used here. In 1968 the difference was 4.1 percentage points. For the whole period, there is slightly less price increase than long-run productivity experience would suggest. Some small catch-up of prices over wage costs could be in store, maintaining price inflation at a slightly higher rate than current wage changes would predict for a while. But this is highly 
conjectural and, in any case, a minor factor in the inflation outlook. Looking at consumer prices, one sees a quantitatively far bigger improvement in store as the current discrepancy between increases in the deflator and the more rapid increases in the CPI is eliminated. Then the CPI will begin to change by approximately the difference between the growth of wages and of productivity.

Wage changes have been larger thus far in 1970 than most observers would have expected. By the third quarter, they were very near the predictions from equation (3). But if my downward adjustment in that equation's predictions to allow for its average errors in the past two years was appropriate, then recent wage changes have been larger than one would have expected using the labor market model developed here. If the unemployment rate settles at around 5.5 percent and the CPI moves into line with wage changes, I would expect inflation to slow to a 2.5 percent rate, but not for several quarters yet. If the equation is correct without adjustmentimplying that 1969 wage developments remain something of a mystery - the eventual inflation rate would be 3.0 percent.

In the longer view, demographic changes by themselves should keep the trade-off over the next several years about where it is now. The large changes in the relative composition of the labor force that have occurred should not continue to occur, primarily because the large group of younger workers will be getting older. But neither will they be reversed. If the tradeoff is to improve over this period, it will have to be as a result of changing relative unemployment rates among the age-sex groups. And recent experience gives no reason to hope for this development without explicit policy actions to bring it about.

\section{Policy Implications}

Economists have long recognized that management of aggregate demand could reduce the unemployment problem to an essentially structural one. The expansion of demand in the late 1960s and the way labor markets responded to it make it clear that that point had been reached in the last years of the decade. Despite the intense total demand for labor that existed, and the tightest overall job market since World War II, unemployment disparities did not narrow. 
The need to do something about large unemployment disparities, particularly the high unemployment rates among young people, has been recognized as a social issue. The results presented here isolate the inflationary consequences of these unemployment patterns and show them to be substantial.

It should be emphasized that the weighting scheme presented here carries no implications about who should be unemployed. To choose a target value for the weighted unemployment rate, or for the combined index, is to ignore the whole dilemma of the trade-off and settle for an inflation target instead. Society may feel more responsible for some kinds of unemployment than others, or for the unemployment of some age groups more than others, but that implies some equity, or social, index, not the labor market indexes developed here. One could argue that society's greatest responsibility is to provide an attractive labor market for young, new entrants into the work force. This would be the last step in fulfilling its acknowledged responsibility to prepare the young for a productive adult life. Yet this implies that individuals with the lowest weights in the present measureand the highest unemployment rates of all age-sex groups-would get the highest weights in the social index. I offer this not as a serious index of social preference, but to emphasize the absence of any implied social preference in the weighting scheme that has been used here.

These results certainly carry a mandate for a better and more intensive structural approach to labor markets than now exists. Broad fiscal and monetary policies are effective in shifting an average measure of labor market tightness; but if that was ever enough, it is not enough today. There are many reasons to expect persistent differences in unemployment rates for different labor market groups. To equalize them is an inappropriate and, furthermore, hopeless task for policy makers. ${ }^{16}$ But the deterioration in relative unemployment rates that has occurred cannot be brushed aside as inevitable or voluntary.

Conceivably, better management of final demand could aid direct labor market policies. A change in the composition of final demand, to the extent that it can be related to the composition of labor demand, might help improve the pattern of unemployment rates. Thus one mix of output would be less inflationary than another. But very little is known about what changes

16. See Robert Hall's article in this issue for a discussion of "normal" unemployment differentials among labor force groups. 
in this mix would be most useful or how large the potential improvement from this kind of policy is.

A new effort in the spirit of the wage-price guideposts seems overdue. It offers no direct help on the particular structural problem identified here. But to the extent the trade-off has deteriorated, for whatever reason, the need for a new government policy in this respect has grown; and the present results once again demonstrate that guideposts helped when they were used.

Finally, it should be emphasized that the structural changes identified here do not imply that a high unemployment policy has any greater merit now than it ever did. Unemployment rates in each' group respond to changes in the average unemployment rate as they always have. To choose a higher average unemployment rate as a target for policy is to choose higher unemployment rates for all labor force groups. What is needed is not a way to rationalize unemployment, but a way to reduce it where it is now highest.

\section{APPENDIX \\ Variables in the Model \\ of Wage Changes}

SeVeral VARIABLES USED in the model of wage changes developed here require a fuller description than was given in the text.

\section{The Weighting Index}

The index used for weighting labor force variables is

$$
I_{i}=J_{i} K_{i},
$$

where $J_{i}$ is the ratio of average manhours worked by persons in the $i$ th age-sex group to the average hours worked by males aged $35-44$, and $K_{i}$ is the ratio of average hourly earnings of employed persons in the $i$ th group to the average for males aged 35-44. Annual estimates of $J_{i}$ and $K_{i}$ were obtained from Edward Denison. For the purposes of this paper, variations 
through time were insignificant. A summary of the average values of $\boldsymbol{I}_{\boldsymbol{i}}$ (where males aged $35-44=1.00$ ) for the postwar period is given below: ${ }^{1}$

$\begin{array}{ccc}\text { Age group } & \text { Male } & \text { Female } \\ \text { 16-19 years } & 0.20 & 0.27 \\ \text { 20-24 years } & 0.57 & 0.38 \\ \text { 25-64 years } & 0.95 & 0.43 \\ \text { 65 and over } & 0.55 & 0.30\end{array}$

\section{Weighted Unemployment}

The weighted unemployment rate is

$$
U^{*}=\frac{\sum I_{i} V_{i}}{\sum I_{i} L_{i}}
$$

where $V_{i}$ is the number of unemployed and $L_{i}$ the number in the labor force in the $i$ th group and the sums are taken over all age-sex groups.

\section{Unemployment Dispersion}

As shown in the text, dispersion was measured by

$$
D U^{*}=\sum \frac{L_{i}^{*}}{L^{*}}\left|\frac{U_{i}^{*}-U^{*}}{U^{*}}\right|,
$$

where $U^{*}$ is defined as above and

$$
\begin{aligned}
U_{i}^{*} & =I_{i} U_{i} \\
L_{i}^{*} & =I_{i} L_{i} \\
L^{*} & =\sum I_{i} L_{i} .
\end{aligned}
$$

\section{The Wage Adjustments}

Two adjustments are made to the official data on compensation per manhour. The first is described by Robert J. Gordon and adjusts for the effects of overtime pay and interindustry shifts. ${ }^{2}$ The second adjusts for the changing age-sex composition of employment.

1. The weighted unemployment rate $U^{*}$ was actually formed using a more detailed age breakdown than is shown here for $I_{i}$ and using annual estimates of $I_{i}$ rather than the postwar averages shown. Because these refinements made little difference, all further calculations, such as those behind the dispersion index and the adjustment to the wage variable discussed below, used the index shown here.

2. "Problems in Predicting the Rate of Inflation." 
This second adjustment corrects the average hourly compensation data for relative shifts in employment among workers in different age-sex groups. It takes account of the differences in average hourly compensation among these groups as measured by $K_{i}$, the wage portion of the weighting index $I_{i}$. The adjustment to the wage change variable has the form

$$
k=\frac{\sum I_{i} \Delta E_{i}}{\sum I_{i} E_{i}}-\frac{\sum K_{i} \Delta E_{i}}{\sum K_{i} E_{i}}
$$

where $E_{i}$ is employment in the $i$ th group and the change in employment $\Delta E_{i}$ is measured over the four quarters spanned by the wage change variable. In forming the adjusted wage variable $w^{*}$ used in the regressions, the adjustment $k$ is subtracted from the percentage change in the official data on average compensation per manhour.

\section{Social Insurance Contributions}

Total compensation of employees is defined as

$$
W=T+\bar{W},
$$

where $T$ is employers' contributions for social insurance and $\bar{W}$ is other compensation (out of which employees' contributions are deducted). If $R$ is defined as $T / W$, the variable $c_{t}$ used in the wage equation is formed as

$$
c_{t}=\frac{R_{t}-R_{t-4}}{1-R_{t-4}} .
$$

This satisfies the identity

$$
w_{t}=\bar{w}_{t}+c_{t},
$$

where $w$ and $\bar{w}$ are the four-quarter percentage changes in $W$ and $\bar{W}$. The coefficient estimated for $c_{t}$ can be shown to be approximately equal to the fraction of $T$ that is not borne by $\bar{W}$. If the coefficient exceeds 1.0 , the excess indicates the fraction of employees' contributions that is passed forward. 


\section{Comments and Discussion}

Charles Schultze: The weighted unemployment index that George Perry devised is an interesting new concept. Because bodies are weighted by hours and relative wages, it is virtually a wage-gap index-in effect, the difference between the actual wage bill and the potential wage bill, expressed as a ratio to the potential wage bill. It is an interesting companion to the GNP gap. I want to concentrate primarily, however, on Perry's other major analytical device - the dispersion index.

The relationship of unemployment to the rate of wage change combines two structural relations: (1) Unemployment is negatively related to the excess demand for labor; and (2) the rate of wage increase depends positively on the excess demand for labor. The relationship of excess demand to unemployment is convex to the origin, since unemployment cannot go lower than zero, but there is no upper limit on excess demand. The relation between the rate of wage increase and excess demand is usually assumed to be positively sloped and linear. The convex shape usually assumed for the relationship between unemployment and rates of wage increase reflects the convexity of the relationship between excess demand and unemployment. This makes sense for the total labor market or for any completely segmented labor market.

If, however, there is substitutability, the relationship of excess demand to unemployment is still convex to the origin but that of excess demand and wage increases could assume a concave shape. If the aggregate unemployment rate is constant while tightness keeps increasing in a particular labor market, a given increase in excess demand in that market may lead to a smaller acceleration in the rate of wage increase. If there is growing tightness in one labor market-which means, given total unemployment, a 
growing surplus in another area-it pays firms in the tight market to restructure jobs rather than to keep increasing the rate of wage increase. In order for a rise in dispersion (again, given total unemployment) to lead to a larger rate of change in wages, the extra dispersion must lead to an addition to the rate of wage increase for groups experiencing a fall in unemployment that is greater than the decrease in the rate of wage increase for groups experiencing a rise in unemployment.

The theoretical argument that greater dispersion intensifies the rate of wage increase must then rest on the hypothesis that the combined relationship is not offsetting and therefore is still convex. My point is that the convexity is not necessarily expected on theoretical grounds, when individual labor markets with some substitutability are analyzed. This leads to the practical point that stronger proof is necessary in demonstrating a dispersion effect, because there are no compelling a priori reasons for expecting it.

The rise in the dispersion index over recent years could stem from two causes: First, it could reflect particular changes over time in the relative weights on the various groups. But Perry shows that this is not the reason. The second cause is the true one: widening over time of the unemployment differentials among groups. Now there are two reasons why the unemployment differences could widen. In the first place, widening unemployment rates could occur because of continuing changes in the composition of the labor force that outrun the ability of employers to adapt. This development must depend on the rates of change; it must level off once the proportions settle down. However, the figures in Table 1 do not demonstrate a close relationship between the change in labor force proportions and the relative unemployment rates among groups.

There is an alternate explanation of the phenomenon that gives Perry's results and that could explain some of the widening unemployment differences, but it does not confirm a dispersion hypothesis. It depends on the shift in the composition of unemployment that Perry stresses, but it depends on the particular direction of that shift rather than on the increase in dispersion. It is a sociological hypothesis-and it troubles my soul to dabble in sociology, particularly of this brand. Nevertheless, suppose some segments of the labor force have rapidly rising minimum reservation prices for their services relative to their marginal productivity; over time, the wages required to induce them to offer their services would become further and further out of line with their marginal productivity. They would show up increasingly as unemployed, but their excess supply impact on the mar- 
ket is substantially weakened. Specifically, among teenagers and young adults in the inner cities there may have been a revolution of rising expectations. Teenagers and young adults are inclined to say: "I don't want those sweat jobs." There has been increased availability of nonwork assistance, under conditions that apply pretty high implicit marginal tax rates to labor income. Another way to say this is that even after Perry's weighting, a systematic differential remains in the relationship of the rate of wage increase to excess demand for different groups. And most important, the relationship for some groups has been changing over time.

If the percentage of total unemployment accounted for by youth goes up, as it has, from 31 percent in 1956 to 50 percent in 1969, Perry's results emerge. But on my hypothesis this would have nothing to do with dispersion per se, but would reflect rather the revolution of rising expectations. Perry would still be correct in warning us of a shift to the right in the Phillips curve. But if my tentative and hypothetical argument is correct, then shifting the Phillips curve back to the left is not primarily a short-run problem of job training and location but a much more difficult long-run problem of motivation and expectations.

Robert Solow: Perry's equation (3) performs well and is plausible. It is probably the best wage equation one can buy nowadays. It makes better sense to me than the various explanations resting on hidden unemployment, since those who stop seeking work probably exercise much less influence on wages. But I want to promote some skepticism, or at least a suspension of judgment, on the grounds that this type of alteration of wage equations may involve a lot of jobbing backwards to fit the facts of recent experience.

Perry's thesis is perfectly straightforward. He wants us to believe that a given unemployment rate (as officially measured) exerts a different degree of downward pressure on money wages, depending on the age-sex composition of the unemployed. Unemployed women and youths have a relatively weak influence on wages because they are offering fewer hours of work and fewer dollars' worth of work per hour. According to his calculations, it takes $3 \frac{1}{2}$ teenage girls to push on wages as much as one prime-age man does. It then follows that any given measured unemployment rate puts less downward pressure on wages now than it did ten or fifteen years ago, because it is now made up of relatively more women and youth. Not only are there more of these people in the labor market, but their relative unemployment experience has become worse.

Perry argues this in part because he is looking for some way to explain 
the rapid wage increases of the past few years. I assume that any wage equation relying on the conventional unemployment rate underestimates recent wage increases. Two things are done that improve the recent fit of the wage equations. One is the use of weighted unemployment instead of conventional unemployment. The second is the dispersion index, on which I share some of Charles Schultze's reservations. Uneven incidence of unemployment might conceivably put more downward pressure on wages if the unemployment shifted to groups with extraordinarily low or extraordinarily steep Phillips curves among themselves. Finally, the profits effect on wages-which Perry found important in his earlier work-has disappeared. Presumably the low profits of recent years would make it even harder to account for the rapid wage rise of 1969-70.

So I have to be suspicious of equation (3), even though it performs well and seems plausible, because of the element of jobbing backwards in looking for something that would explain recent history. One could single out other factors in an effort to track recent experience. Schultze offered one hypothesis. Another example would be the duration of unemployment. People who have been unemployed a long time put more downward pressure on wages because they are more willing to undercut going wage rates in order to get a job. The duration of unemployment has fallen during the four years of full employment that we have experienced, and tends to lag current events, so it might help to explain what has been happening recently. One might hunt for a worldwide cause, since the problem Perry is trying to explain seems to be popping up in other places as well. The rate of wage increase in the United Kingdom is faster now than would have been expected after such a long period of relatively high unemployment. And I gather much the same thing is true in Sweden. None of these explanations looks better to me than Perry's. But the nature of the effort to explain recent experience makes me want to suspend a final judgment until more evidence rolls in. Still, I should emphasize that if I needed a wage equation tomorrow, I'd use Perry's.

R. A. Gordon: I agree with Perry's main conclusion that a 4 percent overall unemployment rate implies a tighter labor market now than it did in the 1950s. As has been suggested, one can think of a variety of reasons why this might be so, not necessarily the specific reasons that Perry gives. One hypothesis is that the length of time that a tight labor market has obtained makes a difference. I tried to test this duration factor but there is only one degree of freedom, because there is only one period like the late sixties. 
Age-sex composition has changed and made a difference. The 1967 unemployment rates with the 1967 weights on age and sex resulted in a 3.85 percent unemployment rate. If the 1956 weights for age, sex, and color are applied to 1967, the adjustment for color reduces the 3.85 only to 3.83 percent. The proportion of blacks in the labor force has not changed the unemployment rate very much, despite their high unemployment rate. Adjusting 1967 to the 1956 sex composition then reduces the unemployment rate from 3.83 to 3.71 , or by 0.12 percentage point. If, in addition, the 1967 labor force is adjusted to the 1956 age composition, the rate drops an additional 0.14 point so that the 3.85 percent unemployment rate in 1967 is reduced to 3.57 if the age, sex, and race weights of the previous period had applied.

If age-sex composition makes a difference, this implies something about the process of wage determination. It implies something about the key role of the prime-age male group in that process. The unemployment rate of white prime-age men may have fallen so much absolutely and relatively in the late sixties that the push upward on their wages spilled over into other groups, even though unemployment rates of these other groups have worsened relative to the national rate.

Perry's weighting of unemployment rates by relative wage levels implies that transmission of wage changes from tight to looser labor markets is not made in terms of percentage changes. If the transmission is in terms of percentage changes rather than dollars and cents, is weighting really necessary? It is my impression that when labor markets tighten, low wages generally tend to rise relatively more rapidly in percentage terms than do high wages. As to the use of the dispersion measure, it might be worth looking at the cyclical, as well as secular, behavior of this measure. It has a regular cyclical pattern that differs for age, sex, and color, and also for occupation and industry. In addition, there are the secular changes Perry concentrates on, which unquestionably show deterioration since 1958. From 1966 to 1969, the dispersion index takes a big jump. Mobility apparently is getting much better among occupations but worsening between sexes-so to speak-and among the young. I agree with Perry that the rising share of youth and women in the labor force has served to increase the upward pressure on wages for a given overall unemployment rate.

Finally, I am not impressed by the results on the guideposts, and still believe the weight of the evidence in explaining the 1962-66 period is on the side of the hidden unemployment thesis. For 1966-69, I agree with the general approach of the Perry paper, stressing labor force composition and 
dispersion, but I would add the long duration of a low unemployment economy as another factor.

George Perry: In response to Robert Solow, I can only report that the intellectual history of weighted unemployment and dispersion is not primarily a matter of hunting for some handy factor to explain rapid wage increases. I regard the weighted unemployment rate as so entirely plausible a priori that I need no ulterior motivation to make that amendment to the standard unemployment rate. I also consider the dispersion index a quite plausible amendment to standard unemployment, to signify that the standard rate is not telling us the same thing today as it was at some other time. A given unemployment rate composed of a much tighter labor market in one area and a much looser one in another ought to be telling a different story. Whether the dispersion index should have as much power as it does in my results is another question, and I fall back on the basic facts. I tried a time trend and various other things, and they didn't reduce the estimated impact of dispersion.

Let me say to R. A. Gordon that this paper was not designed to present new tests of the guidepost proposition. I report the results from a variety of equations: By and large, the guideposts showed up with the right sign and some measure of significance; hidden unemployment did not. I have never seen theoretical or empirical evidence that convinces me of the hidden unemployment effect on wages.

I agree completely with Schultze's point that the widening differentials between the employment rates of young people and of adults shift the Phillips curve as I have indicated whether they arise from an inability of employers to adapt to the changed labor force composition-the demand side-or from a changing reservation price on the part of young people looking for jobs - the supply side. Indeed, if it is the latter, the change is presumably more inflationary, since the labor market for younger workers is then tighter at a given unemployment rate.

\section{General Discussion}

R. J. Gordon felt that Perry's verdict against hidden unemployment was inconclusive, because the hidden unemployment variable did not enter Perry's equation in the nonlinear way the other unemployment variables did, and because the guidepost variable was used simultaneously with it. 
Franco Modigliani reported encouraging results from wage equations that separate the union and nonunion sectors. The union sector takes account of the number of negotiations in any given period. He found no evidence that the guideposts had worked in either sector.

Charles Holt, Franco Modigliani, and Charles Schultze suggested alternative ways in which the dispersion variable might be constructed. It was generally agreed that the best form of the index depended on one's theoretical views about labor market operations. Holt and Modigliani also would have preferred results based on one-quarter, rather than fourquarter, wage changes. Another suggestion, made by Saul Hymans, was that lagged as well as current unemployment should be introduced into the equation. 